\title{
Utilization of medicinal cannabis for pain by individuals with spinal cord injury
}

\author{
Michael Stillman ${ }^{1} \cdot$ Maclain Capron ${ }^{2} \cdot$ Michael Mallow ${ }^{2} \cdot$ Tracy Ransom $^{2} \cdot$ Kristin Gustafson $^{2} \cdot{\text { Alison Bell }{ }^{3}}^{3} \cdot$ \\ Daniel Graves ${ }^{2}$
}

Received: 2 May 2019 / Revised: 7 June 2019 / Accepted: 26 June 2019

(c) The Author(s), under exclusive licence to International Spinal Cord Society 2019

\begin{abstract}
Study design A cross-sectional multi-center study using an on-line survey addressing utilization, knowledge, and perceptions of medicinal cannabis (MC) by people with spinal cord injury (SCI).

Objective To characterize differences between current (CU), past (PU), and never users (NU) of MC with SCI; to determine why people with SCI use MC; to examine reports of MCs' efficacy and tolerability by individuals with SCI.

Setting Three academic medical centers in the United States.

Methods Comparison of demographic and attitudinal differences between CU, PU, and NU and differences in the groups' reports of pain, health, and quality of life (QOL). Evaluation of utilization patterns and perceived efficacy of MC among CU and PU and reports of side effects of MC versus prescription medications. Data were analyzed using either Chi Square, distribution-free exact statistics, or $t$-tests for continuous data.

Results Among a nationwide sample $(n=353)$ of individuals with SCI, NU were less likely than CU and PU to believe that cannabis ought to be legalized and more likely to endorse risks of use. Current users and PU reported greater pain interference in daily life than did NU, but there were no between group differences in QOL or physical or emotional health. Current users and PU took MC to address pain (65.30\%), spasms (63.30\%), sleeplessness (32.70\%), and anxiety (24.00\%), and $63.30 \%$ reported it offered "great relief" from symptoms. Participants reported that MC is more effective and carries fewer side effects than prescription medications.
\end{abstract}

Conclusions Medicinal cannabis is an effective and well-tolerated treatment for a number of SCI-related symptoms.

\section{Introduction}

Despite being legal in 31 states, medicinal cannabis (MC) remains relatively understudied. It is known that just over

Supplementary information The online version of this article (https:// doi.org/10.1038/s41394-019-0208-6) contains supplementary material, which is available to authorized users.

Michael Stillman

michael.stillman@jefferson.edu

1 Departments of Rehabilitation Medicine and Internal Medicine, Sidney Kimmel Medical College of Thomas Jefferson University, Philadelphia, PA, USA

2 Department of Rehabilitation Medicine, Sidney Kimmel Medical College of Thomas Jefferson University, Philadelphia, PA, USA

3 Department of Occupational Therapy, College of Rehabilitation Sciences, Thomas Jefferson University, Philadelphia, PA, USA
$1 \%$ of adult Americans use $\mathrm{MC}$ [1] and that the vast majority of them are seeking relief from severe pain or muscle spasms [2, 3]. There is evidence that $\mathrm{MC}$ is effective in relieving chronic pain $[4,5]$, chemotherapy induced nausea [6, 7], and spasticity in Multiple Sclerosis [4, 8, 9]. Several studies have suggested that use of MC is associated with reduced need for narcotic and non-narcotic pain medications [10-12].

Spinal cord injury (SCI) is often attended by pain and spasticity [13-15]. Between 64 and $88 \%$ of people with SCI live with chronic pain [16-19], and as pain is associated with poor social functioning, community participation, and overall quality of life, it is frequently listed among the top health concerns of individuals living with SCI [20-22]. While MC might effectively address the pain and spasticity of SCI, its potential uses and benefits have been inadequately studied. Three trials have investigated cannabis' effects on pain in SCI. Rintala et al. [23] found that MC was ineffective for relief of sub-lesional neuropathic pain, 
Wilsey et al. [24] demonstrated efficacy for short-term (not chronic) pain relief, and while Wade et al. [25] showed that MC yields significant improvements in pain, spasticity, and spasms, their subjects had a mix of neurological disorders and there was no sub-group analysis of the 4 participants with SCI.

Several authors have interrogated utilization patterns of recreational and medicinal cannabis among people with SCI. Drossel et al. surveyed 244 community dwelling individuals with SCI, finding that just under one-quarter used cannabis and that many sought relief from pain $(70.4 \%)$ and spasticity $(46.3 \%)$ [26]. Andresen et al. reported that among 48 active cannabis users with SCI in Denmark, pain and spasticity were the second and third most cited reasons for use and nearly $60 \%$ described their symptom relief as "good" or "very good" [27]. In a survey of 147 individuals with SCI, Cardenas et al. [28] found that just under $20 \%$ were current MC users and that while it afforded substantial pain relief, most reported that it lasted just hours. Hawley et al. described common reasons for, methods of, and side effects of cannabis use among 27 people living with SCI [29].

While each of these studies has substantively contributed to the literature, all four groups surveyed subjects from limited geographic areas, introducing potential biases based on attitudes toward, legal status of, and availability of cannabis. Further, none of the authors examined how attitudes toward cannabis use may affect individuals' utilization patterns nor how MC users compare its perceived efficacy to that of prescription medications. These represent important persistent gaps in the literature.

We developed an on-line survey addressing adults living with SCI's use and knowledge of MC and their perceptions of its risks and benefits (Appendix A). It contained 88 questions, the majority of which were multiple choice, 19 of which invited free-text responses, and 6 of which utilized a 10 -point Likert Scale. The first paper to have been published from this data set interrogated attitudes toward recreational and medicinal cannabis among individuals living with SCI [30]. Most respondents felt that cannabis is safe for use, has potential therapeutic benefits, and ought to be legalized, however substantial pluralities expressed concerns about health-related and social risks of use, and a majority thought cannabis use was attended by legal risks. In this paper, we sought to answer three main questions: (a) which characteristics among individuals with SCI are associated with being a never user (NU), a past user (PU), or a current user (CU) of $\mathrm{MC}$; (b) why and for which conditions do people with SCI choose to use MC, and; (c) how do current and past MC users with SCI describe its efficacy. In attempting to understand what motivates or dissuades people with SCI from using MC and whether cannabis offers people with SCI substantial relief from bothersome symptoms, we hoped to provide a foundation for further efficacy research and advocacy work.

\section{Methods}

\section{Survey development}

This study utilized a cross sectional multi-center survey methodology that has been described in our prior publication [30]. The authors reviewed existing surveys and manuscripts [1, 3, 26, 27, 31] addressing perceived risks and benefits of $\mathrm{MC}$ use, utilization patterns among $\mathrm{MC}$ users, and primary reasons for use of MC. We also used established pain and quality of life questionnaires taken from the International Spinal Cord Injury Pain and Quality of Life Basic Data Sets [32, 33]. We then received input from experts in the areas of neuropathic pain, MC use, and spinal cord injury medicine seeking to understand how MC users obtain and administer the agent, their risk of attendant substance abuse, and the evolution of attitudes toward MC use. Based on this preliminary work, we developed a survey with four primary foci: (a) participants' attitudes toward and utilization of recreational and $\mathrm{MC}$; (b) their experiences with other controlled and illicit substances; (c) their perceptions of the risks and benefits of MC use, and; (d) their knowledge of recreational and MC. We solicited feedback on the survey's content and usability from Thomas Jefferson University's SCI Consumer Ethics Advisory Board-a group composed exclusively of individuals living with SCI - then submitted the instrument for IRB approval. For the purposes of the survey, "medicinal cannabis" was defined as cannabis used to treat a medical condition or symptom, regardless of how it was obtained or who had recommended it.

Of note, this manuscript, while drawing upon the same dataset used in a previous publication, sought to answer an entirely different and unique set of questions. The authors were cautious not to present redundant data.

\section{Survey distribution}

The survey was administered electronically (SurveyMonkey Inc, San Mateo, CA, www.surveymonkey.com) and no identifying data were collected. We distributed the survey to SCI consumer mailing lists maintained by Thomas Jefferson University, University of Washington at Seattle, and University of Alabama at Birmingham. This effort yielded 246 responses. A second "reminder" email was sent 4 weeks after the first and yielded an additional 107 responses for a total " $n$ " of 353. The final subject pool included participants from 39 states in the United States. Inclusion criteria included being an adult with SCI and being able to access 
and complete an internet-based survey. There were no stated exclusion criteria. Consent to participate was obtained by having potential subjects read an explanation of the study - including express permission to stop at any pointthen click a link to access it. The three institutions' email lists included 2315 potential respondents. Given our final "n" of 353 , our formal response rate was $15.25 \%$.

\section{Data analysis}

Survey responses were reviewed for completeness and each section's results were analyzed based on number of responses. For purposes of analysis, participants' data were grouped into three user categories of current MC user (CU), past MC user (PU), or never used MC (NU). For certain analyses - particularly when attempting to delineate factors associated with never use of cannabis-responses from current and past users were combined and defined as "present or past user of MC." For other analyses, the three groups were treated separately. Individual survey items were evaluated for which test would be appropriate. The three choices were Chi Square, distribution-free exact statistics, or $t$-tests for continuous data.

\section{Results}

A total of 353 people with SCI responded to the survey and $274(77.60 \%)$ were completed in their entirety. All answers from incomplete surveys were included in analyses, hence, the " $\mathrm{n}$ " for certain responses was less than 353 and are provided, where appropriate. The mean age of respondents was 52.74 years (Table 1), average age at injury was 35.25 years, $62.50 \%$ identified as male $(36.50 \%$ as female and $1.0 \%$ as transgender), and the majority $(60.20 \%)$ had a college or advanced degree. A sizable minority $(37.20 \%)$ of participants reported "working for pay," $43.60 \%$ were retired, $74.20 \%$ lived in either a suburban or an urban area, and with 11 (3.1\%) exceptions, all respondents reported living in a private residence.

The majority $(85.10 \%)$ identified trauma (sports, assault, motor vehicle crash, fall, or "birth injury or other traumatic cause") as the etiology of their spinal cord injury or dysfunction, $4.10 \%$ required ongoing or "as needed" ventilatory assistance, and just over half (52\%) had cervical level injuries. While 18\% reported having American Spinal Injury Association (ASIA) Impairment Scale (AIS) A injuries, most respondents $(53.60 \%)$ were unable to classify their injuries.

One hundred eight participants $(30.40 \%)$ reported currently using MC, $42(11.80 \%)$ reported past use, and 130 (36.60\%) had never used MC. Seventy-five individuals $(21.10 \%)$ did not answer the question and were excluded from related analyses. Current and past users were no more 


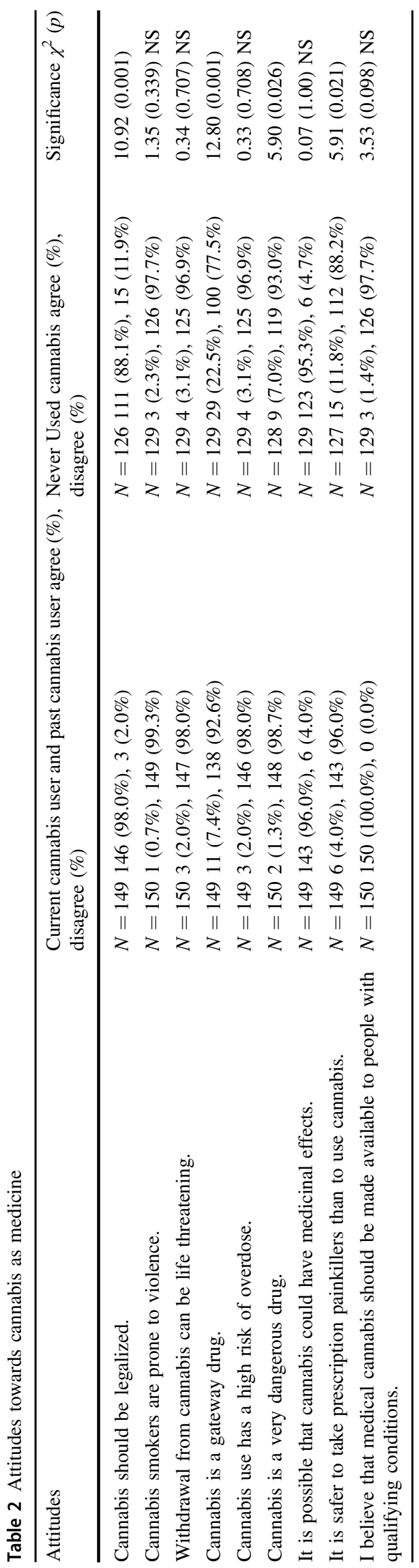

likely than never users to have family members that have struggled with addiction $(\mathrm{CU}+\mathrm{PU}=61.90 \%$; $\mathrm{NU}=$ $65.10 \% ; \chi^{2}=0.31, p=0.618$ ), to have family members who have had legal troubles due to alcohol or drug use $\left(\mathrm{CU}+\mathrm{PU}=37.70 \% ; \mathrm{NU}=35.20 \% ; \chi^{2}=0.19, p=0.707\right)$, or to have abused drugs or alcohol in the past $(\mathrm{CU}+\mathrm{PU}=$ $35.80 \%$; $\left.\mathrm{NU}=38.30 \% ; \chi^{2}=0.18, p=0.708\right)$. Never users were less likely than current and past users to agree that cannabis should be legalized (CU $+\mathrm{PU}=98.00 \%$; $\mathrm{NU}=$ $88.10 \% ; \chi^{2}=10.92, p=.001$ ) (Table 2) and more likely to believe that cannabis is a "gateway drug" $(\mathrm{CU}+\mathrm{PU}=$ $7.40 \% ; \mathrm{NU}=22.50 \% ; \chi^{2}=12.80, p=0.00$ ), a "very dangerous" drug $\left(\mathrm{CU}+\mathrm{PU}=1.30 \%\right.$; $\mathrm{NU}=7.00 \% ; \chi^{2}=5.90$, $p=0.026$ ), and that it is safer to take prescription pain killers than to use $\mathrm{MC}(\mathrm{CU}+\mathrm{PU}=4.00 \%$; $\mathrm{NU}=11.80 \%$; $\left.\chi^{2}=5.91, p=0.021\right)$. There was widespread agreement among participants that cannabis could have medicinal effects $\left(\mathrm{CU}+\mathrm{PU}=96.00 \%\right.$; $\mathrm{NU}=95.30 \% ; \chi^{2}=0.07, p=$ $1.00)$ and that its use carries either no or only slight health risks $\left(\mathrm{CU}+\mathrm{PU}=91.20 \%\right.$; $\mathrm{NU}=83.60 \% ; \chi^{2}=3.61, p=$ 0.067). There were no significant differences in perceptions of social or legal risks between the user groups.

To assess subjects' reports of pain, health, and quality of life, we utilized a 10-point Likert scale, grouping answers 0-3 as "low interference," 4-6 as "some interference," and 7-10 as "extreme interference." In comparing responses of current and past MC users (combined $n=124$ ) with those of never users $(n=117)$, there were no significant differences in pain's interference with day-to-day activities $\left(\chi^{2}=6.76, p=0.034\right)$, $\operatorname{mood}\left(\chi^{2}=2.14, p=0.344\right)$, or ability to sleep $\left(\chi^{2}=0.70\right.$, $p=0.704)$, in assessments of life satisfaction $\left(\chi^{2}=2.576\right.$, $p=0.276)$ or in satisfaction with physical $\left(\chi^{2}=0.32, p=\right.$ 0.854 ) or emotional health $\left(\chi^{2}=0.26, p=0.880\right)$ (Table 3 ).

Among current $(n=92)$ and past users $(n=27)$, mean age of first MC use was 43.12 years. A large majority $(65.50 \%)$ of current and past users reported using or having used MC at least 3-5 days per week (29.40\% reported "several times a day"), and while $64.3 \%$ have or had used MC for 5 years or fewer $(30.20 \%<1$ year), $10.9 \%$ have or had used it for greater than 20 years. There were no demographic or injury-specific differences between current and past MC users and never MC users.

Most current $(n=99)$ and past users $(n=30)$ inhaled $\mathrm{MC}(\mathrm{CU}=63.60 \%$; $\mathrm{PU}=53.30 \%)$ or used sprays or tinctures $(\mathrm{CU}=11.10 \%$; $\mathrm{PU}=23.30 \%)$. Sixty-four percent use or used MC because it "helps with [their] condition," $48 \%$ in hopes that MC would help reduce their use of other prescription medications, $34 \%$ because prescription medications had failed, $22.70 \%$ because it had been recommended by a physician, and $22.70 \%$ because it had been recommended by a friend. Current and past users reported using $\mathrm{MC}$ to address pain (65.30\%), spasms (63.30\%), sleeplessness (32.70\%), and anxiety $(24.00 \%)$. When asked 


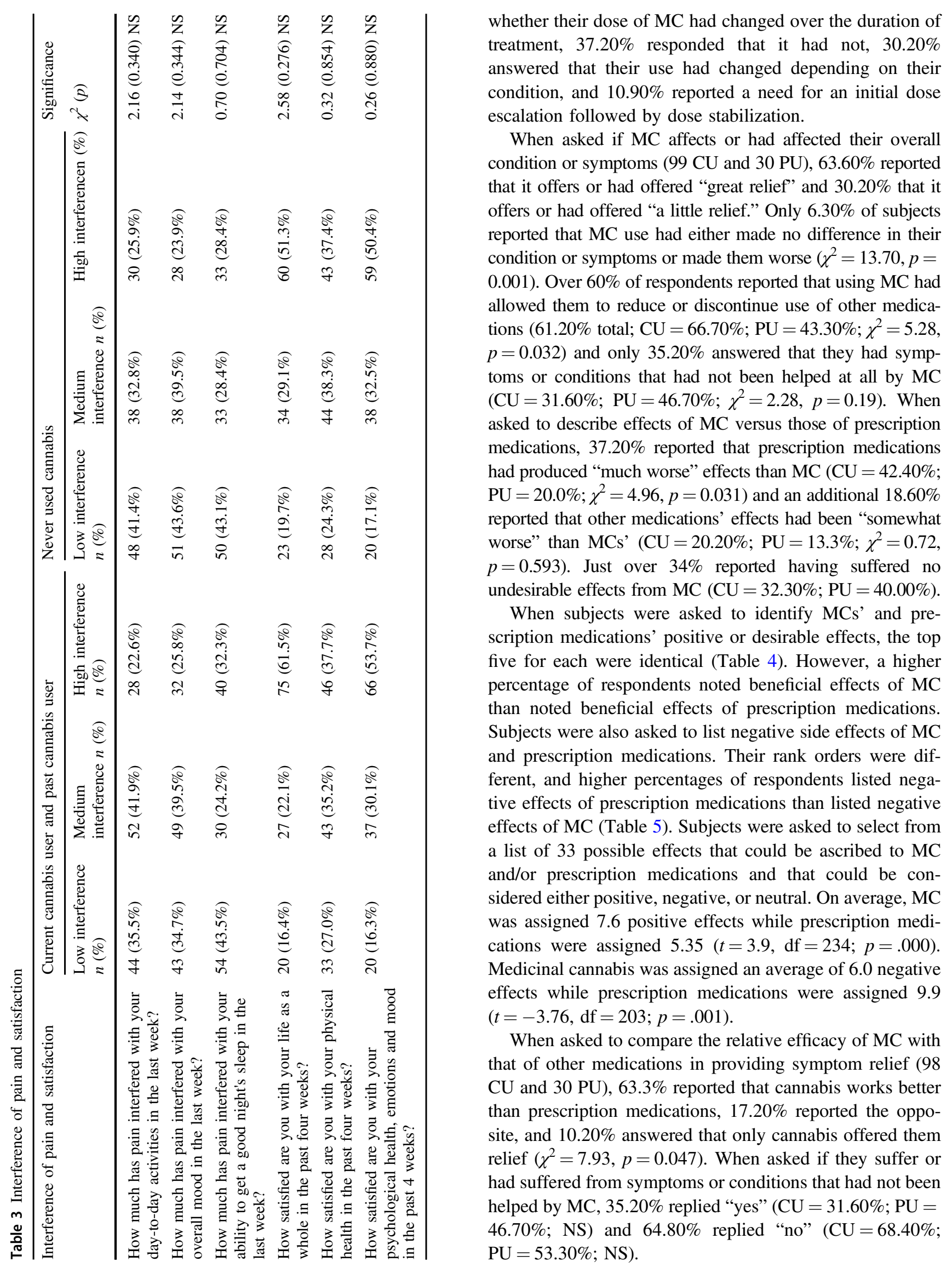


Table 4 Positive effects of medications on symptoms following SCI

\begin{tabular}{|c|c|c|c|c|c|}
\hline \multirow[t]{3}{*}{ Positive effects } & \multicolumn{5}{|c|}{ Type of medication } \\
\hline & \multirow[b]{2}{*}{ Rank } & \multicolumn{2}{|c|}{ Cannabis* } & \multicolumn{2}{|c|}{ Prescription** } \\
\hline & & Count & Percentage & Count & Percentage \\
\hline Muscle relaxation & $1 \mathrm{st}$ & 112 & $90.3 \%$ & 85 & $72.6 \%$ \\
\hline Promotes sleep & 2nd & 101 & $83.5 \%$ & 58 & $51.3 \%$ \\
\hline $\begin{array}{l}\text { A feeling of } \\
\text { well being }\end{array}$ & $3 \mathrm{rd}$ & 89 & $75.4 \%$ & 52 & $46.0 \%$ \\
\hline Decreased anxiety & 4 th & 83 & $69.7 \%$ & 50 & $43.5 \%$ \\
\hline Increased appetite & 5 th & 64 & $53.3 \%$ & 28 & $25.2 \%$ \\
\hline
\end{tabular}

$*_{n}=128$

$* * n=126$

Table 5 Negative effects of medications on symptoms following SCI

\begin{tabular}{|c|c|c|c|c|c|c|}
\hline \multirow{3}{*}{$\begin{array}{l}\text { Negative } \\
\text { Effects }\end{array}$} & \multicolumn{6}{|c|}{ Type of medication } \\
\hline & \multicolumn{3}{|c|}{ Cannabis* } & \multicolumn{3}{|c|}{ Prescription $* *$} \\
\hline & Rank & Count & Percentage & Rank & Count & Percentage \\
\hline Dry mouth & $1 \mathrm{st}$ & 66 & $54.5 \%$ & 1 st & 62 & $51.7 \%$ \\
\hline $\begin{array}{l}\text { Residual bad } \\
\text { taste in mouth }\end{array}$ & 2nd & 34 & $29.6 \%$ & 12 th & 33 & $29.5 \%$ \\
\hline Dehydration & 3rd & 33 & $28.7 \%$ & 5 th & 50 & $42.4 \%$ \\
\hline Memory loss & 4th & 31 & $27.2 \%$ & 11 th & 35 & $32.1 \%$ \\
\hline $\begin{array}{l}\text { Lethargy/lack } \\
\text { of energy }\end{array}$ & 5 th & 30 & $26.3 \%$ & 4th & 52 & $46.4 \%$ \\
\hline Drowsiness & 9th & 25 & $21.7 \%$ & 2nd & 56 & $49.1 \%$ \\
\hline Constipation & 14th & 20 & $17.2 \%$ & $3 \mathrm{rd}$ & 53 & $46.3 \%$ \\
\hline
\end{tabular}

$*_{n}=128$

$* * n=126$

Past MC users were asked why they had stopped. A minority of respondents $(16.70 \%)$ said it had never controlled their symptoms, but none answered that it had lost effect, that side effects were limiting, that it was unaffordable, that it was difficult to ensure a supply, or that its use was illegal. In free text responses, past MC users cited fear of physician repercussions, drops in blood pressure, variability in effect, social stigma, loss of employment, and risk of losing federally funded housing as reasons for having stopped.

\section{Discussion}

This study is the first to examine how personal beliefs influence MC use and to compare its perceived efficacy and tolerability to that of prescription medications. A number of our findings are notable.

First, there seem to be demonstrable differences between current and past MC users and those who have never used MC. In contrast to Drossel et al., in which subjects who used MC were more likely to report pain interference with life than were non-MC users [26], our groups did not differ in pain interference or in self-assessments of emotional or physical health. However, current and past users were less concerned than never users with a number of perceived risks of cannabis use, notably that it is a "gateway" or a "very dangerous" drug. Clinicians in states with legal MC must understand that some patients who may find it beneficial may hold both solid (legal risks) and less well established (safety relative to that of other medications) fears about its use, and that those concerns may make them less likely to consider treatment with $\mathrm{MC}$.

Second, our data seem to indicate that MC has variable efficacy. Past users were less likely than CUs to report having been able to reduce use of other medications while they were taking $\mathrm{MC}$ and to endorse that prescription medications' side effects were worse than MCs'. Further, fully $16 \%$ of them stopped using MC because they found it ineffective. There was no requirement in this survey that MC be purchased from a medical distributor, and there is variable efficacy of cannabis products taken from the same plant. Therefore, it is expected that there would be considerable variation in the quality, potency, and chemical components of the cannabis our subjects utilized. Even so, these data suggest that there may simply be people who are more or less likely to respond to and benefit from MC therapy, and that ongoing monitoring and evaluation by clinicians is essential to effective prescribing. Future work may also focus on which individuals with SCI are more or less likely to respond to MC therapy.

Third, while other studies have documented MCs' usefulness in reducing use of other medications and in treating chronic pain, this is the first study to compare perceived effectiveness of MC to prescription medications in treating SCI-related symptoms. While Drossel et al., Andresen et al., and Hawley et al. documented reasons for MC among individuals with SCI [26, 27, 29], only Cardenas et al. [28] and Andresen interrogated its perceived efficacy in relieving pain. None of these studies asked subjects to directly compare MCs' perceived efficacy and tolerability with that of prescription medications. Among our subjects, over $90 \%$ of CU and PU reported "a little" or "great" relief from symptoms with MC and $61.20 \%$ claimed that MC had allowed them to reduce or discontinue use of other medications. Further, large majorities of these subjects $(73.4 \%)$ reported that cannabis is more effective (or exclusively effective) and better tolerated than other medications they had been offered. While gabapentinoids [34-36], Botulinum Toxin A[37], and antidepressants [38, 39] have been shown to have modest effects on chronic pain in individuals with SCI, the medical community's ability to adequately relieve SCI-related pain remains limited. Our findings support the notion that MC may have an important role-either as adjuvant therapy or as monotherapy - in treating a number of common symptoms experienced by individuals living with SCI. There is certainly 
a need for expedited clinical trials evaluating efficacy of MC in chronic SCI, and no justification for cannabis' continued classification as a Schedule 1 drug, a designation indicating that it has no accepted medical use.

Finally, we were taken by former users' stated reasons for having discontinued using MC. While some of them seem to have found MC less effective than did current users, very few of them reported having stopped using it due to lack of effect. Rather, they relayed stories of fear of continued use, of variable and unpredictable effects (potentially addressed through regulation), of stigma, and of loss of employment and government-subsidized housing. It seems, then, that some individuals with SCI-related symptoms may benefit from MC treatment but are dissuaded from using it by their fears of facing potentially drastic repercussions.

\section{Study limitations}

This study has several important limitations. First, we did not ask participants which medications they had taken in the past and/or currently take. As a result, it is difficult to assess the adequacy of attempts to control subjects' symptoms (particularly pain and spasticity) before they initiated MC use, and to determine whether they are using $\mathrm{MC}$ as adjuvant or monotherapy. Second, we did not assess how much MC participants used. While a majority of CU and PU reported using MC several times each week, it is unclear how much they took with each administration. Hence, it is impossible to use this work to estimate appropriate or effective dosing of MC. Third, our distribution method certainly introduced biases into our subject pool. While we did not inquire about annual family income or ethnicity, we know that over $60 \%$ of our participants had college or advanced degrees. Depending on duration of injury, between 10.90 and $43.70 \%$ of individuals with SCI have completed a college degree [40]. It is certainly possible that people who have completed more school have different attitudes toward cannabis use, though we were unable to find literature to substantiate this. Further, the very topic of this survey may have attracted participants with a history of or a strong interest in using MC. While $30.40 \%$ of our subjects were CU of MC, just under $10 \%$ of adult Americans report having using cannabis in the past year [41]. Finally, our low response rate is a clear limitation, as only $15.25 \%$ of individuals to whom the survey was emailed responded, and under one-third of them were active MC users. This being said, this study provides evidence that some individuals with SCI and associated symptoms find relief with MC, that they find MCs' side effects largely tolerable and less onerous than those of prescription medications, and that some people with SCI may avoid using or discontinue use of MC not because it is ineffective, but, rather, due to perceived and real repercussions of continued use.

\section{Data archiving}

The datasets generated and analyzed during the current study are available from the corresponding author on reasonable request.

Author contributions MS was responsible for researching and developing the survey, submitting the project to the IRB, coordinating survey distribution, and drafting the manuscript. MC assisted with survey development, was primarily responsible for data analysis, and helped draft the manuscript. MM was responsible for researching and developing the survey, building the on-line survey, and drafting the manuscript. TR was responsible for researching and developing the survey, helping analyze the data, and drafting the manuscript. KG was responsible for researching and developing the survey, helping analyze the data, and drafting the manuscript. $\mathrm{AB}$ was responsible for researching and developing the survey, helping analyze the data, and drafting the manuscript. DG was responsible for researching and developing the survey, helping analyze the data, and drafting the manuscript.

\section{Compliance with ethical standards}

Conflict of interest The authors declare that they have no conflict of interest.

Statement of ethics This study was reviewed by the Thomas Jefferson University Institutional Review Board and deemed exempt. We certify that all applicable institutional and governmental regulations concerning the ethical use of human volunteers were following during the course of this research.

Publisher's note: Springer Nature remains neutral with regard to jurisdictional claims in published maps and institutional affiliations.

\section{References}

1. Choi NG, DiNitto DM, Marti CN. Nonmedical versus medical marijuana use among three age groups of adults: Associations with mental and physical health status. Am J Addict 2017;26:697-706.

2. National Academies of Sciences, Engineering, and Medicine; Health and Medicine Division; Board on Population Health and Public Health Practice; Committee on the Health Effects of Marijuana: an Evidence Review and Research Agenda. The health effects of cannabis and cannabinoids: the current state of evidence and recommendations for research. Washington, DC: The National Academies Press; 2017.

3. Bonn-Miller MO, Boden MT, Bucossi MM, Babson KA. Selfreported cannabis use characteristics, patterns and helpfulness among medical cannabis users. Am J Drug Alcohol Abus 2014;40:23-30.

4. Whiting PF, Wolff RF, Deshpande S, et al. Cannabinoids for medical use: a systematic review and meta-analysis. J Am Med Assoc. 2015;313:2456-73.

5. Andreae MH, Carter GM, Shaparin N, et al. Inhaled cannabis for chronic neuropathic pain: a meta-analysis of individual patient data. J Pain 2015;16:1221-32.

6. Smith LA, Azariah F, Lavender VT, Stoner NS, Bettiol S. Cannabinoids for nausea and vomiting in adults with cancer receiving chemotherapy. Cochrane Database Syst Rev. 2015. https://doi.org/ 10.1002/14651858.CD009464.pub2.

7. Badowski ME. A review of oral cannabinoids and medical marijuana for the treatment of chemotherapy-induced nausea and 
vomiting: A focus on pharmacokinetic variability and pharmacodynamics. Cancer Chemother Pharm. 2017;80:441-9.

8. Leocani L, Nuara A, Houdayer E, et al. Sativex $((\mathrm{R}))$ and clinicalneurophysiological measures of spasticity in progressive multiple sclerosis. J Neurol 2015;262:2520-7.

9. Koppel BS, Brust JC, Fife T, et al. Systematic review: Efficacy and safety of medical marijuana in selected neurologic disorders: Report of the guideline development subcommittee of the american academy of neurology. Neurology 2014;82:1556-63.

10. Boehnke KF, Litinas E, Clauw DJ. Medical cannabis use is associated with decreased opiate medication use in a retrospective cross-sectional survey of patients with chronic pain. J Pain 2016;17:739-44.

11. Bradford AC, Bradford WD. Medical marijuana laws reduce prescription medication use in medicare part D. Health Aff (Millwood) 2016;35:1230-6.

12. Wen H, Hockenberry JM. Association of medical and adult-use marijuana laws with opioid prescribing for medicaid enrollees. JAMA Intern Med 2018;178:673-9.

13. Charlifue SW, Weitzenkamp DA, Whiteneck GG. Longitudinal outcomes in spinal cord injury: Aging, secondary conditions, and well-being. Arch Phys Med Rehabil 1999;80:1429-34.

14. New PW. Secondary conditions in a community sample of people with spinal cord damage. J Spinal Cord Med 2016;39:665-70.

15. Anson CA, Shepherd C. Incidence of secondary complications in spinal cord injury. Int J Rehabil Res. 1996;19:55-66.

16. Adriaansen JJ, Ruijs LE, van Koppenhagen CF, et al. Secondary health conditions and quality of life in persons living with spinal cord injury for at least 10 years. J Rehabil Med 2016;48:853-60.

17. Wollaars MM, Post MW, van Asbeck FW, Brand N. Spinal cord injury pain: the influence of psychologic factors and impact on quality of life. Clin J Pain. 2007;23:383-91.

18. Ataoglu E, Tiftik T, Kara M, Tunc H, Ersoz M, Akkus S. Effects of chronic pain on quality of life and depression in patients with spinal cord injury. Spinal Cord 2013;51:23-26.

19. Nagoshi N, Kaneko S, Fujiyoshi K, et al. Characteristics of neuropathic pain and its relationship with quality of life in 72 patients with spinal cord injury. Spinal Cord 2016;54:656-61.

20. Kennedy P, Lude P, Taylor N. Quality of life, social participation, appraisals and coping post spinal cord injury: a review of four community samples. Spinal Cord 2006;44:95-105.

21. Lo C, Tran Y, Anderson K, Craig A, Middleton J. Functional priorities in persons with spinal cord injury: using discrete choice experiments to determine preferences. $\mathbf{J}$ Neurotrauma 2016;33:1958-68.

22. Anderson KD. Targeting recovery: priorities of the spinal cordinjured population. J Neurotrauma 2004;21:1371-83.

23. Rintala DH, Fiess RN, Tan G, Holmes SA, Bruel BM. Effect of dronabinol on central neuropathic pain after spinal cord injury: A pilot study. Am J Phys Med Rehabil. 2010;89:840-8.

24. Wilsey BL, Deutsch R, Samara E, et al. A preliminary evaluation of the relationship of cannabinoid blood concentrations with the analgesic response to vaporized cannabis. $J$ Pain Res 2016;9:587-98.

25. Wade DT, Robson P, House H, Makela P, Aram J. A preliminary controlled study to determine whether whole-plant cannabis extracts can improve intractable neurogenic symptoms. Clin Rehabil 2003;17:21-29.

26. Drossel C, Forchheimer M, Meade MA. Characteristics of individuals with spinal cord injury who use cannabis for therapeutic purposes. Top Spinal Cord Inj Rehabil 2016;22:3-12.

27. Andresen SR, Biering-Sorensen F, Hagen EM, Nielsen JF, Bach FW, Finnerup NB. Cannabis use in persons with traumatic spinal cord injury in denmark. J Rehabil Med 2017;49:152-60.

28. Cardenas DD, Jensen MP. Treatments for chronic pain in persons with spinal cord injury: a survey study. J Spinal Cord Med 2006;29:109-17.

29. Hawley LA, Ketchum JM, Morey C, Collins K, Charlifue S. Cannabis use in individuals with spinal cord injury or moderate to severe traumatic brain injury in colorado. Arch Phys Med Rehabil 2018;99:1584-90.

30. Stillman M, Mallow M, Ransom T, Gustafson K, Bell A, Graves D. Attitudes toward and knowledge of medical cannabis among individuals with spinal cord injury. Spinal Cord Ser Cases. 2019;5:6-019-0151-6.

31. Cuttler C, Spradlin A. Measuring cannabis consumption: Psychometric properties of the daily sessions, frequency, age of onset, and quantity of cannabis use inventory (DFAQ-CU). PLoS One. 2017; 12:e0178194.

32. Widerstrom-Noga E, Biering-Sorensen F, Bryce TN, et al. The international spinal cord injury pain basic data set (version 2.0). Spinal Cord 2014;52:282-6.

33. Charlifue S, Post MW, Biering-Sorensen F, et al. International spinal cord injury quality of life basic data set. Spinal Cord 2012;50:672-5.

34. Schug SA, Parsons B, Almas M, Whalen E. Effect of concomitant pain medications on response to pregabalin in patients with postherpetic neuralgia or spinal cord injury-related neuropathic pain. Pain Physician 2017;20:E53-E63.

35. Cardenas DD, Nieshoff EC, Suda K, et al. A randomized trial of pregabalin in patients with neuropathic pain due to spinal cord injury. Neurology 2013;80:533-9.

36. Mehta S, McIntyre A, Dijkers M, Loh E, Teasell RW. Gabapentinoids are effective in decreasing neuropathic pain and other secondary outcomes after spinal cord injury: A meta-analysis. Arch Phys Med Rehabil 2014;95:2180-6.

37. Han ZA, Song DH, Oh HM, Chung ME. Botulinum toxin type A for neuropathic pain in patients with spinal cord injury. Ann Neurol. 2016;79:569-78.

38. Mehta S, Guy S, Lam T, Teasell R, Loh E. Antidepressants are effective in decreasing neuropathic pain after SCI: a metaanalysis. Top Spinal Cord Inj Rehabil 2015;21:166-73.

39. Vranken JH, Hollmann MW, van der Vegt MH, et al. Duloxetine in patients with central neuropathic pain caused by spinal cord injury or stroke: A randomized, double-blind, placebo-controlled trial. Pain 2011;152:267-73.

40. National spinal cord injury statistical center. Spinal cord injury facts and figures at a glance. 2016. www.nscisc.uab.edu. Accessed 16 Dec 2017.

41. Prevalence of marijuana use among U.S. adults doubles over the past decade. 2015. http://www.niaaa.nih.gove/news-events/newsreleases/prevalence-marijuana-use-among-us-adults-doubles-overpast-decade. Accessed 15 Feb 2019. 